\title{
Change needed on measures of impact
}

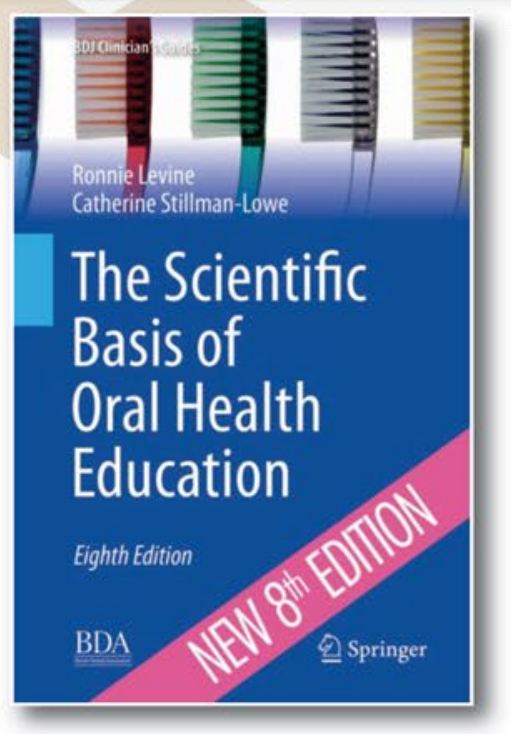

\section{The Scientific Basis of Oral Health Education}

\section{Ronnie Levine and \\ Catherine Stillman-Lowe}

- Provides a sound evidence base on the main aspects of oral health

- Uses a simple scheme to indicate the strength of supporting scientific evidence in each condition

- New: A broad international consensus of dental expert opinion

$96 \mathrm{pp}$ | 21 colour illustrations

Price: $\$ 74.99$

BDA Member Price: $₫ 58.12$

BDA members save over $20 \%$

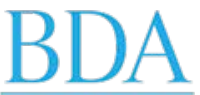

HOW TO ORDER

Buy now from

shop.bda.org/the-scientific

-basis-of-oral-health

-education-8th-edition

Free P\&P for BDA members

Springer
Experts have voiced support for changes to how the impact of dental research is measured to allow for a more representative picture and wider recognition of the potential influence of studies.

Several advantages of a change to the current system were highlighted during a symposium event entitled Altmetrics - The New Impact Factor? that took place on 25 July 2018, during the International Association for Dental Research meeting held in London, but for which a full transcript has just been made available on the $B D J^{\prime}$ 's website (supplementary online information). ${ }^{1}$

The discussion looked at the strengths and weaknesses of the current 'impact factor' approach when assessing the quality of scientific literature (a measure reflecting the yearly average number of citations to a published article) and the possibility of using a different approach known as Altmetrics to either replace or supplement it in the future.

Altmetrics or 'alternative metrics' are a broad group of metrics, capturing various parts of the impact that a research paper or work can have, such as news articles, science blogs, Wikipedia, Twitter, Facebook and other social media mentions, and citations in scholarly literature.

Professor Will Giannobile, Najjar Endowed Professor \& Chair at University of Michigan School of Dentistry, USA, who is also Editor of the Journal of Dental Research, spoke at the event, saying that Altmetrics could be a highly useful approach.

'Essentially, Altmetrics looks at a weighting of a variety of measures that indicate the attention a particular manuscript/article has received,' he said. 'It is therefore considered to be a more comprehensive measure of impact.

'The scientific impact factor - the two-year measure - is really only one metric of a journal's stature. I really do hope, personally, that it's not emphasised so much in the future because I think it is important to look at a composite of other measures. I think it
[Altmetrics] is the most comprehensive tool to assess an article's importance and, certainly, something I hope will evolve over time.'

Fellow panel member Professor Paul Speight, Emeritus Professor at the University of Sheffield, said: 'Across the whole of the research community, the use of metrics remains contested and open to lots of misunderstanding. Peer review, despite its flaws, continues to command the most widespread support among researchers for people to judge their outputs and the quality of their research.

'Metrics should support not supplant expert judgement.'

Fellow speaker Professor Liz Kay, Professor from the University of Plymouth and Editor of the journal Evidence-Based Dentistry, said: 'Very often, papers are cited in another paper because it's findings are being disputed or refuted, or the methodology used is being challenged. Therefore, logic tells us that IF (impact factors) or citation rate cannot possibly act as a measure of quality of a piece of research.

'Altmetrics explores and makes available source materials and looks at what is being said by whom, about a piece of research. The measures can actually show when a piece of research is altering the field of study in some way or even better, when it is actually having an effect on the health, or the behaviour of the profession or public'

Dr Stephen Hancocks, Editor-in-Chief of the $B D J$, also speaking at the event, said: 'Altmetrics assess a wide range of methods for delivering information. The traditional metrics are often slow to accrue - two to five years. You've got no idea what impact your paper is having. With Altmetrics you know immediately. Within hours, you can start to measure the impact of what you've had published.'

\section{References}

1. Eaton K A, Giannobile W, Speight P, Kay E, Hancocks S. Proceedings of a Symposium - Altmetrics - The New Impact Factor? held on 25 July 2018, during the International Association for Dental Research meeting held in London. $\mathrm{Br}$ Dent J 2019; 226: Supplementary online information.

\section{BDA AGMs}

The Branch Annual General Meeting (AGM) of the East of Scotland Branch will take place on Wednesday, 20 March 2019 at the Royal Scots Club, 29-31 Abercromby Place, Edinburgh EH3 6QE, followed by a lecture on cardiac health and oral health with Alex Crighton. The meeting begins at 19.00. To book, please visit: https://www.bda.org/events/branches-sections/Pages/east-of-scotland-branch-wednesday-20-march-2019.aspx. 